\title{
The Regression Analysis of Stock Returns at MSE
}

\author{
Zoran Ivanovski \\ University of Tourism and Management in Skopje, Skopje, Macedonia \\ Nadica Ivanovska \\ Central Cooperative Bank, Skopje, Macedonia \\ Zoran Narasanov \\ Vienna Insurance Group, Skopje, Macedonia
}

\begin{abstract}
The linear regression and correlation analysis of daily returns of several stocks and stock-exchange index at Macedonian Stock Exchange (MSE) provide evidence for statistical significance of the stocks' daily returns at MSE. Statistical analysis was focused to determine the character of relationship between the 10 most liquid stocks at MSE using ten-year time-series of daily stocks' closing price and for the Macedonian Stock Exchange Index (MBI-10). The analysis of daily stock returns provided $R^{2}$ values and confirmed that the proportion of the total correlation in the dependent variable (one stock price) can be explained by the independent variable (other stock price) as well as that accurate forecasting of one stock price movements enables reliable prediction of other stock future price at MSE. Some implications for stock valuation are drawn.
\end{abstract}

Keywords: stock, return, correlation, regression, volatility

\section{Introduction}

Macedonian Stock Exchange (MSE) was established in September 1995, but its real start was with the first ring of Stock-Exchange bells on March 28, 1996. MSE started on November 1, 2001 to calculate Macedonian Stock Exchange Index (MBI), which consists of five most liquid stocks at MSE. MBI was price not weighted index, and as a first index it finished its function as aggregate indicator for stock exchange movement quantification.

On January 4, 2005, a new MSE index was introduced (MBI-10), as weighted average indicator. It enables using market capitalization more realistically following price movements at MSE. MBI-10 is index of 10 most liquid stocks on MSE official market segment. Stock Index Committee regularly (two times per year) and ad-hoc (in special circumstances) made update of MBI-10 structure in accordance with market conditions. With the start of MBI-10 calculation, MSE stopped MBI calculation. Starting from 2006, MSE regularly calculates Bond Price Index (OMB).

MSE's short history strongly affects security valuation that usually required long-term time series (more than 10 years). With the end of 2014 MBI-10 we have 10 years data for MBI-10 daily closing prices. This makes regression analysis results more reliable that can be used for MSE stocks. We focus our research on stocks that contained MBI-10. The basic task of our research is to examine the basic parameters and character of returns at MSE as an emerging market.

Zoran Ivanovski, Ph.D., full professor, University of Tourism and Management in Skopje. Email: z.ivanovski@utms.edu.mk. Nadica Ivanovska, Ph.D., assistant professor, Central Cooperative Bank.

Zoran Narasanov, Ph.D., assistant professor, Winner Insurance, Vienna Insurance Group. 
The remainder of this paper is structured into three sections. In Section 2, we present a theoretical review about the returns at emerging markets. Section 3 presents empirical results from a regression analysis of stocks at MSE. Section 4 summarizes the main conclusions.

\section{Literature Overview}

There is a difference between returns in emerging capital markets from returns in developed markets (Bekaert \& Harvey, 1995): average returns are higher, correlations with developed market returns are low, returns are more predictable and volatility is higher. Finance literature has many studies for volatility of developed markets but a limited number of studies for emerging markets (Shiller, 1990; Bolt \& Milobedzki, 1994; Flores \& Szafarz, 1997).

Rouwenhorst (1998) argued, in his paper, that the factors that drive cross-sectional differences in expected stock returns in emerging equity markets are qualitatively similar to those that have been found in developed equity markets. In a sample of more than 1,700 firms from 20 countries, he found that emerging market stocks exhibit momentum, small stocks outperform large stocks, and value stocks outperform growth stocks. There is no evidence that high beta stocks outperform low beta stocks.

Moreover, emerging market countries are particularly interesting because of their relative isolation from the capital markets of other countries (Rouwenhorst, 1998). Therefore, he argued that the relative segmentation of emerging markets provides a unique opportunity to examine cross-sectional variation of stock returns: if the return factors found in a group of relatively isolated markets are the same as in developed markets, it becomes more likely that these factors are fundamentally related to the way in which investors set prices in financial markets around the world.

The underlying dynamic of returns is either given exogenously or is based on the assumption that returns have independent and identical distributions. However, such characteristics do not fit adequately with the empirically-observed features of financial returns and investor choice (Copeland, Weston, \& Shastri, 2004).

In their study for the dynamics of expected stock returns and volatility in emerging financial markets, De Santis and Imrohoroglu (1997) found clustering, predictability, and persistence in conditional volatility, as others have documented for mature markets. However, emerging markets exhibit higher conditional volatility and conditional probability of large price changes than mature markets. Exposure to high country-specific risk does not appear to be rewarded with higher expected returns. They detected a risk-reward relation in Latin America but not in Asia when we assume some level of international integration. They did not find support for the claim that market liberalization increases price volatility.

Kearney and Daly (1998) examined, in their paper, the extent to which the conditional volatility of stock market returns in a small, internationally integrated stock market is related to the conditional volatility of financial and business cycle variables. It employed a low frequency monthly dataset for Australia including stock market returns, interest rates, inflation, the money supply, industrial production, and the current account deficit over the period from July 1972 to January 1994. They argued that among the most important determinants of the conditional volatility of the Australian stock market are found to be the conditional volatilities of inflation and interest rates which are directly associated with stock market volatility, and the conditional volatilities of industrial production, the current account deficit and the money supply which are indirectly associated with stock market conditional volatility. Paper also determines that among these variables, the strongest effect is found to be from the conditional volatility of the money supply to the conditional 
volatility of the stock market. By contrast, no evidence is found of volatility spillover from the foreign exchange market to the stock market in Australia.

MSE was not previously considered in the literature considering stocks return until 2007 by Kovacic (2007), where he derived some conclusions about the volatility of MBI-10 returns series which are characterized with volatility clustering.

\section{Descriptive Statistics}

We analyze 10 years stocks daily returns data at MSE in order to determine stocks' correlation and comprehensive regression analysis. We believe that the provided results will be useful for stocks' valuation. The basic task of our research is to determine the returns character at MSE and identify mutual dependence and correlation of stocks returns. We argue that our findings have practical application for stock value forecast.

We use the sample of 10 stocks from the official market segment of MSE contained in the MBI-10 Index. The 10 selected companies were selected based on their stock market capitalization, their influence in the MBI-10, and the volume traded at MSE, which are as follows: ALK, BESK, GRNT, KMB, MPT, REPL, SBT, STIL, MTUR, and TPFL. The accepted criteria ensured that all economic groups represented in the MSE were under analysis. MSE was the main source of data through the official stock newsletters and annual reports. The time period of 10 years allowed us to make appropriate conclusions. The analysis was performed using the daily closing prices of the traded stocks as well for MBI-10 for the period from December 30, 2004 to December 31, 2014. The base data for MBI-10 is: December 30, $2004=1000$ (when MBI-10 index started).

Using regression analysis, we have determined a strong positive correlation between stocks prices at MSE (most of the values oscillate around 0.90), as shown in Table 1.

Table 1

Correlation Coefficients at MSE

\begin{tabular}{|c|c|c|c|c|c|c|c|c|c|c|c|}
\hline Company & ALK & BESK & GRNT & KMB & MPT & REPL & SBT & STIL & MTUR & TPFL & MBI-10 \\
\hline ALK & 1.00 & & & & & & & & & & \\
\hline BESK & 0.96 & 1.00 & & & & & & & & & \\
\hline GRNT & 0.97 & 0.97 & 1.00 & & & & & & & & \\
\hline KMB & 0.87 & 0.78 & 0.80 & 1.00 & & & & & & & \\
\hline MPT & 0.97 & 0.96 & 0.97 & 0.84 & 1.00 & & & & & & \\
\hline REPL & 0.86 & 0.89 & 0.91 & 0.77 & 0.86 & 1.00 & & & & & \\
\hline SBT & 0.71 & 0.60 & 0.60 & 0.85 & 0.71 & 0.47 & 1.00 & & & & \\
\hline STIL & 0.89 & 0.92 & 0.95 & 0.63 & 0.91 & 0.84 & 0.41 & 1.00 & & & \\
\hline MTUR & 0.96 & 0.95 & 0.97 & 0.81 & 0.95 & 0.90 & 0.62 & 0.91 & 1.00 & & \\
\hline TPFL & 0.96 & 0.97 & 0.96 & 0.78 & 0.95 & 0.83 & 0.63 & 0.91 & 0.94 & 1.00 & \\
\hline MBI-10 & 0.42 & 0.33 & 0.32 & 0.67 & 0.47 & 0.29 & 0.81 & 0.13 & 0.31 & 0.31 & 1.00 \\
\hline
\end{tabular}

Note. Column/Row 1: Stock ISIN code. Columns/Rows 2-12: Correlation coefficients.

Table 1 provides correlations among stocks and MBI-10 at MSE. We can see a lower but still positive correlation among stocks and MBI-10. The difference of correlation among stocks and MBI-10 compared with only mutual stocks correlation coefficients suggests that MBI-10 changes are not immediately followed by the other stocks on MSE. The conclusion about lower statistical significance between stocks' price movements and MBI-10 index daily values raises the question about relevancy of using MBI-10 index for forecasting other stocks' market prices at MSE. This finding will be tested with regression analysis. 
We explore the correlation of MSE stocks' daily returns in order to determine mutual dependence and correlation of stocks returns as tools for stock value forecast. Using regression analysis, we are trying to determine if there is a statistically significant relationship between the variables (two stock prices or daily index values and stock price). We first analyzed the multiple $R$ (coefficient of correlation) and $R$ square $\left(R^{2}\right)$. The $R^{2}$ is the coefficient of determination and tells us the proportion of the total variation in the dependent variable that is explained by the independent variable. If there is a stronger relationship (higher coefficient of determination), it indicates that this relationship is statistically significant and the prediction of the dependent variable will be accurate if we have a good forecast of the independent variable. Using variance statistics, we determine the F-test which confirms if regression analysis is statistically significant. The very low level of significance $F$-value confirms the statistical significance of the analyzed relationship. Next, we look at the $t$-statistics for our regression coefficients. We analyze whether a $t$-statistic coefficient is statistically distinguishable from zero (i.e., statistically significant). The magnitude of the coefficient is not the issue of our interest. If the coefficient for one stock price is significantly different from zero, then we know that the independent value (stock price) is useful in predicting other company stock price. The $t$-statistic is the coefficient of the departure of an estimated parameter from its notional value and its standard error. Obviously, the higher this number, the more confidence we have that the coefficient is different from zero. Generally for large samples, a $t$-statistic greater than 2.00 is significant at the $95 \%$ confidence level or more. We also use the $p$-value to determine the exact confidence level. We calculate the $p$-value by subtracting the $p$-value from 1 to find the confidence level. This number is simply the best point estimate given our set of sample data. We also present the result: lower 95\%. This gives us a range of values between which we can be $95 \%$ sure where the true value of this coefficient lies. Since we are merely using this model for forecasting, the significance of the intercept is not important. In our regression statistics, we asked for $95 \%$ level of confidence.

The descriptive statistics results and regression analysis of daily stock prices at MSE are presented in Tables 2-4.

Table 2

Descriptive Statistics for ALK, BESK, GRNT, and KMB

\begin{tabular}{lllll}
\hline & ALK & BESK & GRNT & KMB \\
\hline Mean & 5,078 & 11,071 & 746 & 3,786 \\
Standard error & 57.55 & 237.82 & 14.10 & 44.20 \\
Median & $4,299.85$ & 7,400 & 573.16 & $3,249.89$ \\
Mode & 1,900 & $5,996.15$ & 90 & 560 \\
Standard deviation & $2,559.65$ & $10,577.22$ & 627.09 & $1,965.78$ \\
Sample variance & $6,551,815.88$ & $111,877,738.9$ & $393,249.68$ & $386,432.3$ \\
Kurtosis & 1.40 & 2.45 & 1.429878 & -0.7222527 \\
Skewness & 1.366062562 & 1.707005518 & 1.4935188 & 0.3592342 \\
Range & $12,493.55$ & $52,089.02$ & $2,852.19$ & $7,654.02$ \\
Minimum & $1,686.68$ & $1,292.91$ & 90 & 420 \\
Maximum & $14,180.23$ & $53,381.93$ & $2,942.19$ & $8,074.02$ \\
Sum & $10,044,716.22$ & $21,898,765.38$ & $1,477,038.7$ & $7,489,096.3$ \\
Count & 1,978 & 1,978 & 1,978 & 1,978 \\
Largest (1) & $14,180.23$ & $53,381.93$ & $2,942.19$ & $8,074.02$ \\
Confidence level (95.0\%) & 112.87 & 466.41 & 27.65 & 86.68 \\
\hline
\end{tabular}


Table 3

Descriptive Statistics for REPL, SBT, STIL, and MPT

\begin{tabular}{lllll}
\hline & REPL & SBT & STIL & MPT \\
\hline Mean & 39,868 & 5,585 & 205 & 43,274 \\
Standard error & 477.96 & 80.85 & 4.03 & 818.67 \\
Median & 39,500 & $3,425.72$ & 154.71 & $27,500.5$ \\
Mode & 7,000 & 2,500 & 92 & 12,500 \\
Standard deviation & $21,257.21$ & $3,596.03$ & 179.41 & $36,410.21$ \\
Sample variance & $451,869,207$ & $12,931,495.08$ & $32,189.42$ & $1,325,703,652$ \\
Kurtosis & -0.301025848 & -1.146 & 1.96 & 2.11 \\
Skewness & 0.258551862 & 0.69 & 1.58 & 1.69 \\
Range & 89,500 & $11,416.12$ & 851.51 & $164,898.22$ \\
Minimum & 5,500 & $1,799.86$ & 16.63 & 10,300 \\
Maximum & 95,000 & $13,215.98$ & 868.14 & $175,198.22$ \\
Sum & $78,859,623.19$ & $11,048,762.73$ & $407,117.7$ & $85,597,340.63$ \\
Count & 1,978 & 1,978 & 1,978 & 1,978 \\
Largest (1) & 95,000 & $13,215.98$ & 868.14 & $175,198.22$ \\
Confidence level (95.0\%) & 937.36 & 158.57 & 7.91 & $1,605.55$ \\
\hline
\end{tabular}

Table 4

Descriptive Statistics for MTUR, TPFL, and MBI-10

\begin{tabular}{llll}
\hline & MTUR & TPFL & MBI-10 \\
\hline Mean & 3,488 & 4,812 & 3,319 \\
Standard error & 47.47 & 82.16 & 43.37 \\
Median & 2,800 & 3,600 & $2,519.70$ \\
Mode & 3,000 & 3,500 & $1,834.28$ \\
Standard deviation & $2,111.22$ & $3,654.37$ & $1,929.11$ \\
Sample variance & $4,457,277.276$ & $13,354,446.45$ & $3,721,490.199$ \\
Kurtosis & 0.874 & 3.460 & 1.623 \\
Skewness & 1.358 & 1.953 & 1.590 \\
Range & $9,113.74$ & $17,819.04$ & $9,057.77$ \\
Minimum & 930 & 1,200 & 1,000 \\
Maximum & $10,043.74$ & $19,019.04$ & $10,057.77$ \\
Sum & $6,899,741.2$ & $9,518,250.73$ & $6,565,544.59$ \\
Count & 1,978 & 1,978 & 1,978 \\
Largest (1) & $10,043.74$ & $19,019.04$ & $10,057.77$ \\
Confidence level (95.0\%) & 93.097 & 161.143 & 85.066 \\
\hline
\end{tabular}

It is obvious from the descriptive statistics results that stocks at MSE have high volatility, positive skewness, and high kurtosis values (only two stocks REPL and SBT have negative kurtosis). The daily return series for all stocks from MSE are leptokurtic, with no exception. This means that significant variations in the daily prices are very common. All MSE stocks have large kurtosis values.

In Table 5, we report the linear regression statistics results for GRNT stock as a dependent variable (multiple $R, R$ square, adjusted $R$ square, standard error, number of observations, df, SS, MS, significance $F$, $t$-statistic, and $p$-value) where BESK stock is an independent variable. 
Table 5

Linear Regression Statistics for GRNT and BESK Stocks

\begin{tabular}{|c|c|c|c|c|c|}
\hline \multicolumn{6}{|l|}{ Regression statistics } \\
\hline Multiple $R$ & $97 \%$ & & & & \\
\hline$R$ square & $93 \%$ & & & & \\
\hline Adjusted $R$ square & $93 \%$ & & & & \\
\hline Standard error & 75.16 & & & & \\
\hline No. of observations & 999.00 & & & & \\
\hline \multicolumn{6}{|c|}{ ANOVA } \\
\hline & $\mathrm{df}$ & SS & MS & $F$ & Significance $F$ \\
\hline Regression & 1.00 & $79,562,607.41$ & $79,562,607.41$ & $14,084.91$ & - \\
\hline Residual & 997.00 & 5,631,839.07 & $5,648.79$ & & \\
\hline \multirow[t]{2}{*}{ Total } & 998.00 & $85,194,446.49$ & & & \\
\hline & Coefficient & Standard error & $t$-statistic & $p$-value & Lower 95\% \\
\hline Intercept & 108.57 & 5.48 & 19.80 & 0.00 & 97.81 \\
\hline BESK & 0.06 & 0.00 & 118.68 & - & 0.06 \\
\hline
\end{tabular}

Note. Significance at the $95 \%$ confidence level.

Table 5 reports the results of analysis for two companies' stocks (Granit and Beton Skopje) from construction industry in the Republic of Macedonia. Values for multiple $R$ (coefficient of correlation) and $R$ square (coefficient of determination, variance) for GRNT daily stocks returns as a dependent variable and BESK as an independent variable are around 1 (0.97 and 0.93 respectively), which gives us the conclusion that there is a statistically significant relationship between the two variables. In fact, there is an almost $100 \%$ significant relationship between the outcomes and the predicted value. The $R^{2}$ tells us that the proportion of the total variation in the dependent variable (GRNT stock market price) can be explained by the independent variable (BESK stock price). Using variance statistics, we determine the $F$-test that confirms the significance of regression analysis. The very low level of significance $F$ confirms the statistical significance of the analyzed relationship. A $t$-statistic is high and confirms significance. We can also see that $p$-value (probability value which explains that results occur randomly) is zero, which means that we are 100\% confident that our coefficient (BESK) is significant for predicting GRNT's stock price changes. There are only $6 \%$ chances that the determined coefficient for BESK can be lower than the coefficient determined in regression analyses.

Table 6 reports multiple regression analysis results where ALK stock price as a dependent variable was tested using other MSE stocks and MBI-10 as independent variables. Our findings are confirmed with high values for adjusted $R$ square and appropriate values of $t$-statistics and $p$-values.

Table 6 provides multiple regression statistics results for ALK stock listed at MSE. Multiple regression analysis is significant (adjusted $R^{2}$ is 94\%) which indicates a high level of relationship between ALK and other MSE stocks prices. Regression statistics confirm our findings (with 95\% level of confidence) that the proportion of the total correlation in the dependent variable (ALK stock market price) can be explained by the independent variables (stock prices of BESK, GRNT, KMB, MPT, REPL, SBT, STIL, MTUR, and TPFL). 
Table 6

Multiple Regression Statistics for ALK Stock

\begin{tabular}{|c|c|c|c|c|c|}
\hline \multicolumn{6}{|l|}{ Regression statistics } \\
\hline Multiple $R$ & $97 \%$ & & & & \\
\hline$R$ square & $94 \%$ & & & & \\
\hline Adjusted $R$ square & $94 \%$ & & & & \\
\hline Standard error & 321.78 & & & & \\
\hline No. of observations & 999.00 & & & & \\
\hline \multicolumn{6}{|c|}{ ANOVA } \\
\hline & $\mathrm{df}$ & SS & MS & $F$ & Significance $F$ \\
\hline Regression & 8.00 & $1,558,065,574.45$ & $194,758,196.81$ & $1,880.90$ & - \\
\hline Residual & 990.00 & $102,509,492.30$ & $103,544.94$ & & \\
\hline \multirow[t]{2}{*}{ Total } & 998.00 & $1,660,575,066.76$ & & & \\
\hline & Coefficient & Standard error & $t$-statistic & $p$-value & Lower 95\% \\
\hline Intercept & $2,052.19$ & 120.48 & 17.03 & 0.00 & $1,815.76$ \\
\hline GRNT & 3.42 & 0.20 & 17.31 & 0.00 & 3.03 \\
\hline KMB & 0.15 & 0.03 & 5.46 & 0.00 & 0.10 \\
\hline MPT & 0.01 & 0.00 & 1.57 & 0.12 & -0.00 \\
\hline REPL & -0.02 & 0.00 & -4.97 & 0.00 & -0.03 \\
\hline SBT & 0.07 & 0.03 & 2.04 & 0.04 & 0.00 \\
\hline STIL & -0.14 & 0.45 & -0.30 & 0.76 & -1.03 \\
\hline MTUR & -0.05 & 0.03 & -1.65 & 0.10 & -0.10 \\
\hline TPFL & 0.07 & 0.03 & 2.37 & 0.02 & 0.01 \\
\hline
\end{tabular}

Note. Significance at the $95 \%$ confidence level.

\section{Conclusion}

This paper contributes to the determination of the character of stocks returns and stocks' valuation at MSE. In particular, we first identify the correlation between stocks at MSE. Using regression analysis, we have determined a strong positive correlation between stocks prices at MSE (most of the values oscillate around 0.90). We can see a lower but still positive correlation among stocks and MBI-10. The difference of correlation among stocks and MBI-10 compared with only mutual stocks correlation coefficients suggests that MBI-10 changes are not immediately followed by the other stocks on MSE.

Linear and multiple regression analysis results lead us to the conclusions that there is statistical significance between stock prices at MSE as well as that regression analysis is a useful tool for forecasting stocks market prices at MSE. We did not detect any difference in our findings when analyzing stocks from the same industry and stocks from different sectors. The $R^{2}$ values confirmed that the proportion of the total correlation in the dependent variable (one stock price) can be explained by the independent variable (other stock price) as well as that accurate forecasting of one stock price movements will lead us to safe valuation and prediction of other stock future prices. Using regression analysis, we find that stock prices movements (as a dependent variable) can be explained by MBI-10 as an independent variable. We determine the statistical significance among MSE stocks and MBI-10 index which leads us to the conclusion that we can use MBI-10 returns for forecasting stock prices at MSE. This finding can be used for portfolio management at MSE. 


\section{References}

Bekaert, G., \& Harvey, C. R. (1995). Emerging equity market volatility. NBER Working Paper No. 5307, pp. 1-79.

Bolt, T. W., \& Milobedzki, P. (1994). The Warsaw Stock Exchange in the period 1991-1993. Qualitative problems of its modelling. Economics of Planning, 27(3), 211-226.

Copeland, T. E., Weston, J. F., \& Shastri, K. (2004). Financial theory and corporate policy (4th ed.). New York, NY: Pearson New International Edition.

De Santis, G., \& Imrohoroglu, S. (1997). Stock returns and volatility in emerging financial markets. Journal of International Money and Finance, 16(4), 561-579.

Flores, R. G., Jr. \& Szafarz, A. (1997). Testing the information structure of Eastern European markets: The Warsaw Stock Exchange. Economics of Planning, 30(2), 91-105.

Kearney, C., \& Daly, K. (1998). The causes of stock market volatility in Australia. Applied Financial Economics, 8(6), 597-605.

Kovacic, Z. J. (2007). Forecasting volatility: Evidence from the Macedonian Stock Exchange. MPRA Paper No. 5319, pp. 1-44.

Rouwenhorst, K. G. (1998). Local return factors and turnover in emerging stock markets. School of Management, Yale University, NBER Series, pp. 1-37.

Shiller, R. J. (1990). Market volatility. Massachusetts and London: The MIT Press. 